\title{
KONSEP KEBUTUHAN PENGHUNI DALAM PEMBANGUNAN HUNIAN SEMENTARA (STUDI KASUS: HUNIAN SEMENTARA PASCA-BENCANA KOTA PALU, INDONESIA)
}

\section{(THE CONCEPT OF RESIDENT NEEDS IN THE CONSTRUCTION TEMPORARY HOUSING (CASE STUDY: POST-DISASTER TEMPORARY HOUSING IN PALU, INDONESIA))}

\author{
Vivi Novianti HY*, Ahmad Sarwadi** \\ *Mahasiswa, Magister Perencanaan Wilayah dan Kota, Fakultas Teknik, Universitas Gadjah Mada \\ Jl. Grafika No.2,Sekip,Yogyakarta, 55281, Indonesia \\ Email: vnoviantihy@mail.ugm.ac.id \\ ** Dosen, Magister Perencanaan Wilayah dan Kota, Fakultas Teknik, Universitas Gadjah Mada \\ Jl. Grafika No.2,Sekip,Yogyakarta, 55281, Indonesia
}

Diterima: 19 Mei 2021; Direvisi: 23 Desember 2021; Disetujui: 24 Desember 2021

\begin{abstract}
ABSTRAK
Gempa bumi yang terjadi di Kota Palu dan sekitarnya pada 28 September 2018 menyebabkan kerusakan pada 66.926 unit rumah. Pemerintah melakukan pembangunan hunian sementara untuk korban yang mengalami kerusakan rumah. Korban bencana telah menghuni hunian sementara kurang lebih selama 2 tahun. Berdasarkan hasil observasi awal (grand tour) ditemukan fenomena perubahan fisik pada hunian sementara. Perubahan fisik yang terjadi menyebabkan hunian sementara berubah dari bentuk aslinya. Penelitian ini bertujuan menemukan wujud perubahan fisik yang terjadi untuk menyusun konsep hunian sementara pada masa tanggap darurat bencana berdasarkan kebutuhan penghuni. Penelitian ini menggunakan metode studi kasus dengan kasus ganda. Metode analisis yang digunakan pada penelitian ini adalah analisis deskriptif. Hasil penelitian ini menunjukkan penghuni hunian sementara melakukan perubahan fisik karena ada kebutuhan penghuni yang kurang dan belum terpenuhi. Hal tersebut disebabkan kurangnya konsep pemenuhuhan kebutuhan penghuni dalam kebijakan pembangunan hunian sementara. Maka diperlukan konsep hunian sementara yang dapat memenuhi kebutuhan penghuni. Konsep kebutuhan pada hunian sementara terdiri atas kebutuhan fisik, kebutuhan psikologis, dan kebutuhan fungsional.
\end{abstract}

Kata kunci: hunian sementara, kebutuhan, perubahan fisik, tanggap darurat.

\begin{abstract}
Earthquake happened in Palu and its neighborhood on September $28^{\text {th }}, 2018$, has destroyed 66.926 houses. Government built temporary housing for the victims suffered from the loss. The victims have been residing in those temporary house for 2 years. Based on grand tour at the research location that has been conducted, physical change phenomena were found. The physical change altered the shape of temporary houses from their original shape. This reaserch aims to find the form of the physical changes to finally develop a concept of temporary housing in disaster emergency response period based on the residents' needs. The method for this reasearch is study case wuth double case. Analysis is performed using descriptive analysis method. The result shows temporary housing residents made the alteration of their house due to the lack or the absence of provision for their need. Those was resulted from the absence of resident needs provision concept in temporary housing development policy. Therefore, the concept is needed in order to provide the resident needs. Concept of needs in the temporary housing consist of physical needs, psychological needs and functional needs.
\end{abstract}

Keywords: temporary housing, emergency response, needs, physical change. 
Konsep Kebutuhan Penghuni Dalam Pembangunan Hunian Sementara (Studi Kasus: Hunian Sementara PascaBencana Kota Palu, Indonesia)

Vivi Novianti HY, Ahmad Sarwadi

\section{PENDAHULUAN}

Gempa bumi dengan kekuatan 7,4 Skala Richter yang terjadi di Kota Palu dan sekitarnya pada tanggal 28 September 2018 telah memicu terjadinya 2 bencana lainnya, yaitu tsunami dan likuifaksi. Bencana ini menyebabkan kerusakan pada 66.926 unit rumah. Pemerintah Provinsi Sulawesi Tengah menetapkan masa tanggap darurat dari tanggal 28 September-26 Desember 2018, dan pada masa ini salah satu tujuan pemerintah adalah menyediakan tempat penampungan dan pembangunan hunian sementara bagi korban yang mengalami kerusakan rumah. Berdasarkan hasil wawancara, penghuni mulai menghuni hunian sementara pada awal tahun 2019, terhitung hingga saat ini penghuni telah menghuni selama 2 tahun. Hasil observasi awal pada lokasi-lokasi hunian sementara di Kota Palu, hunian sementara yang masih dihuni yaitu hunian sementara Lere dan Hunian Sementara Petobo.

Fenomena yang ditemukan pada kedua lokasi yaitu terjadi perubahan fisik pada hunian sementara. Penghuni melakukan perubahan fisik dengan cara penambahan, penggurangan dan penggabungan (lihat gambar 1). Kondisi tersebut menyebabkan hunian sementara berubah dari bentuk aslinya. Fenomana tersebut menunjukkan telah terjadi transformasi pada bentuk hunian sementara, tranformasi didefinisikan sebagai penambahan, pengurangan, dan perpindahan dari suatu elemen pada lingkungan binaan (Habraken, dalam Sesotyaningtyas et al, 2015). Perubahan fisik pada hunian selalu mengarah pada transformasi bentuk hunian, dalam penelitian yang dilakukan oleh Ernawati et al (2011) mengenai proses adaptasi yang mengarah pada peruahan fisik hunian atau tempat tinggal, ditemukan perubahan fisik yang dilakukan penghuni pada rumah susun yaitu dengan menambah sekat atau pembatas ruang. Beberapa penelitian juga telah mengidentifikasi bahwa dalam proses berhuni di perumahan massal penghuni membutuhkan modifikasi untuk mencapai pola bermukim yang sesuai dengan tujuan penghuni (Lutfiah, 2010; Omar et al, 2012 dalam Kurniati dan Kusuma, 2014). Sedangkan dalam penelitian Pramono (2018) perubahan fisik pada hunian tetap dilakukan penghuni dengan cara cara menambah ruang, mengurangi, ruang dan menyatukan ruang.

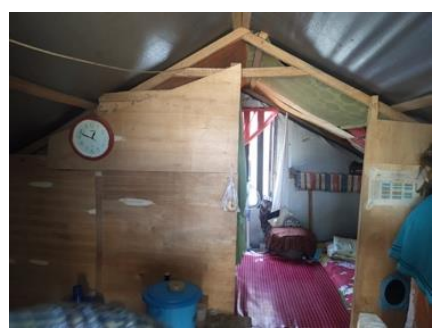

(a)

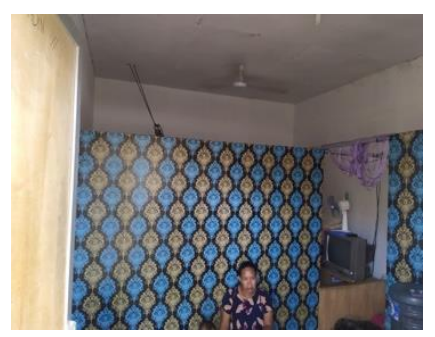

(b)

Gambar 1. Perubahan Fisik pada Hunian Sementara (a) Lere dan (b) Petobo Sumber: Hasil Survei, (2020)

Berdasarkan fenomena yang terjadi, maka timbul sebuah pertanyaan "Mengapa penghuni melakukan perubahan fisik pada hunian sementara?" Asumsi awal peneliti, perubahan fisik terjadi karena ada kebutuhan penghuni yang tidak terpenuhi selama menghuni hunian sementara. Selaras dengan hal tersebut dalam penelitian Lutfiah (2010) perubahan bentuk dan fungsi hunian disebabkan karena keterbatasan ruang untuk setiap perilaku penghuninya dan rendahnya tingkat privasi. Hal serupa juga dijelaskan dalam penelitian Omar, et al (2017), yang menemukan bahwa perubahan fisik rumah disebabkan oleh ketidaklayakan dan ketidaksesuain kondisi rumah dengan kebutuhan penghuninya. Selaras dengan dua penelitian sebelumnya, Rahim dan Hasyim (2018) menemukan perubahan fisik rumah disebabkan oleh tidak adanya privasi antara anggota keluarga dan anggota keluarga dengan tamu dalam hunian, sehingga menghambat perilaku penghuninya. 
Berdasarkan asumsi dan hasil dari penelitian terdahulu, maka perlu ditemukan bentuk perubahan fisik dan alasan penghuni melakukan perubahahan fisik, sehingga dapat dilihat apakah hunian sementara Lere dan Petobo telah memenuhi kebutuhan penghuninya.

\section{METODE}

Pengumpulan data awal dilakukan untuk menemukan fenomena apa yang telah terjadi pada hunian sementara pasca-bencana Kota Palu. Berdasarkan observasi awal (grand tour) kawasan hunian sementara yang masih dihuni yaitu hunian sementara Lere dan Petobo. Fenomena yang ditemukan adalah perubahan fisik pada hunian sementara. Pada hunian sementara Lere kurang lebih terdapat 60 hunian dan Hunian sementara petobo terdapat kurang lebih 80 hunian. Proses wawancara dan observasi di kedua lokasi difokuskan pada 15 hunian, sehingga total sampel berjumlah 30. Penentuan 15 hunian tersebut dilakukan secara purposive, dengan karakter sampel adalah hunian yang telah mengalami perubahan fisik. Peneliti berharap dengan penentuan 15 sampel disetiap lokasi dapat mewakili populasi sampel secara keseluruhan.

Metode yang digunakan untuk menjawab pertanyaan penelitian ini adalah metode analisis deskriptif. Analisis deskriptif digunakan untuk mengelompokkan dan mengkategorikan hasil temuan lapangan. Hasil dari analisis ini adalah menemukan bentuk perubahan fisik, alasan penghuni melakukan perubahan fisik, serta konsep hunian sementara yang dapat memenuhi kebutuhan penghuni.
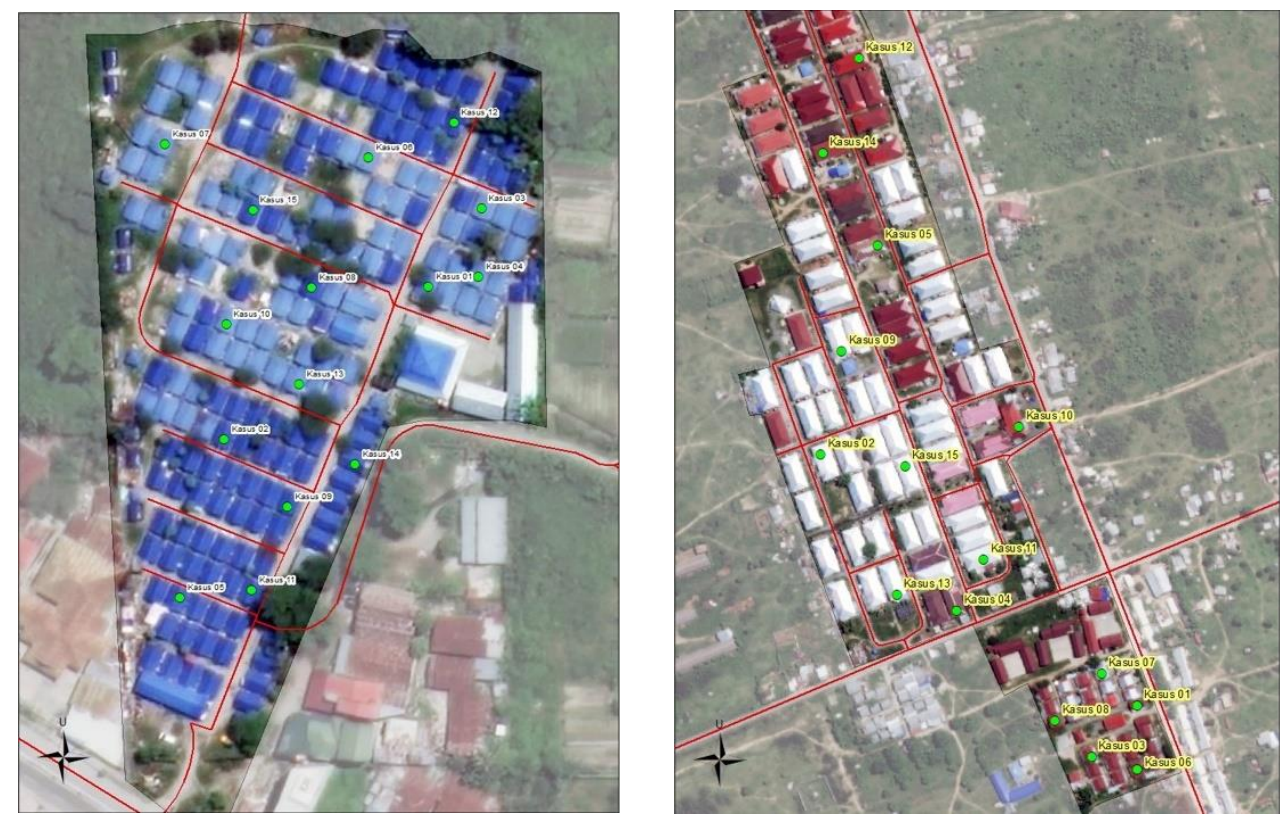

Gambar 2. Kawasan Hunian Sementara Lere dan Petobo Sumber: Hasil Analisis, (2021)

\section{HASIL DAN PEMBAHASAN \\ HASIL}

Hasil observasi di hunian sementara Lere dan Petobo menunjukkan terdapat banyak perbedaan antara kedua hunian. Perbedaan yang paling tampak yaitu pada tipe pola hunian (lihat gambar 3). Hunian sementara Lere memiliki pola hunian kopel sedangkan hunian sementara Petobo memiliki pola hunian deret. 
Konsep Kebutuhan Penghuni Dalam Pembangunan Hunian Sementara (Studi Kasus: Hunian Sementara Pasca-

Bencana Kota Palu, Indonesia)

\section{Vivi Novianti HY, Ahmad Sarwadi}

Tabel 1. Perbedaan antara Hunian Sementara Lere dan Petobo

\begin{tabular}{|l|l|l|}
\hline \multicolumn{1}{|c|}{ Aspek } & \multicolumn{1}{|c|}{ Hunian Sementara Lere } & \multicolumn{1}{c|}{ Hunian Sementara Petobo } \\
\hline Penghuni & $\begin{array}{l}\text { Hunian sementara Lere dihuni } \\
\text { masyarakat yang terdampak } \\
\text { bencana tsunami }\end{array}$ & $\begin{array}{l}\text { Hunian sementara Petobo dihuni } \\
\text { masyarakat yang terdampak bencana } \\
\text { likuifaksi }\end{array}$ \\
\hline Ukuran & Ukuran hunian $3 \times 4$, & Ukuran hunian 3x4 \\
\hline Bentuk bangunan & tidak berpanggung & semi panggung \\
\hline Tipe Pola Hunian & Pola hunian tunggal & Pola hunian petak \\
\hline Fasilitas Hunian & Terdapat tempat dapur & - \\
\hline Fasilitas Bersama & Kamar mandi umum & Dapur umum dan kamar mandi umum \\
\hline
\end{tabular}

Sumber: Hasil Analisis, 2021

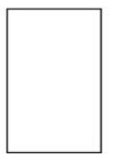

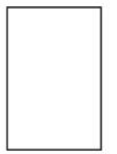

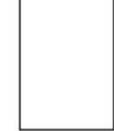

(a)

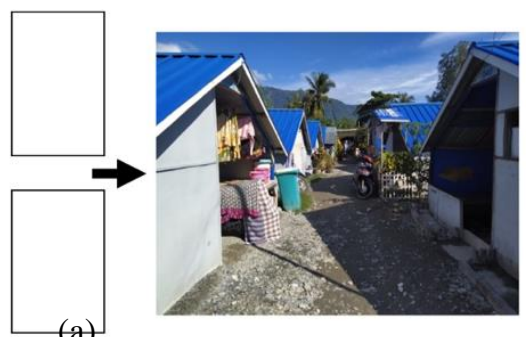

Gambar 3. (a) Lere (b) Petobo

Sumber: Hasil Analisis, (2021)

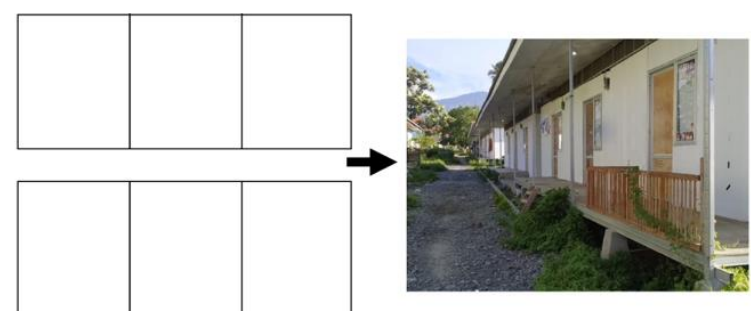

(b)

Tabel 2. Wujud dan Tipologi Perubahan Fisik Pada Hunian Sementara Lere dan Petobo

\begin{tabular}{|c|c|c|}
\hline Tipologi Perubahan Fisik & Wujud Perubahan Fisik & Jumlah Kasus \\
\hline \multicolumn{3}{|l|}{ Lere } \\
\hline $\begin{array}{l}\text { Perubahan dengan menambah } \\
\text { ruang }\end{array}$ & Penambahan sekat & 15 \\
\hline \multirow{6}{*}{ Perubahan pada elemen hunian } & Perubahan pada lantai & 14 \\
\hline & Perubahan pada plafon & 9 \\
\hline & $\begin{array}{l}\text { Perubahan dengan memperbesar } \\
\text { jendela }\end{array}$ & 8 \\
\hline & $\begin{array}{l}\text { Perubahan dengan penambahan } \\
\text { jendela }\end{array}$ & 6 \\
\hline & $\begin{array}{l}\text { Perubahan dengan menganti } \\
\text { pintu }\end{array}$ & 2 \\
\hline & $\begin{array}{l}\text { Perubahan dengan membagi } \\
\text { pintu menjadi } 2 \text { bagian }\end{array}$ & 4 \\
\hline \multirow[t]{2}{*}{$\begin{array}{l}\text { Penambahan ruang dan luas } \\
\text { hunian }\end{array}$} & $\begin{array}{l}\text { Penambahan ruang disertai } \\
\text { dengan penambahan luas hunian }\end{array}$ & 8 \\
\hline & $\begin{array}{l}\text { Penemabahan dinding disertai } \\
\text { dengan penambahan luas }\end{array}$ & \\
\hline \multicolumn{3}{|l|}{ Petobo } \\
\hline $\begin{array}{l}\text { Perubahan dengan menambah } \\
\text { ruang }\end{array}$ & Penambahan sekat & 15 \\
\hline \multirow[t]{2}{*}{ Perubahan pada elemen hunian } & Penambahan terjadi pada pintu & 1 \\
\hline & $\begin{array}{l}\text { Perubahan pada dinding untuk } \\
\text { menambah pintu }\end{array}$ & 1 \\
\hline \multirow[t]{2}{*}{$\begin{array}{l}\text { Penambahan ruang dan luas } \\
\text { hunian }\end{array}$} & $\begin{array}{l}\text { Perubahan disertai dengan } \\
\text { penambahang ruang dan luas } \\
\text { hunian }\end{array}$ & 9 \\
\hline & $\begin{array}{l}\text { Penggabungan hunian untuk } \\
\text { memperluas hunian }\end{array}$ & 2 \\
\hline
\end{tabular}

Sumber: Hasil Analisis,2021

4 | Jurnal Riset Pembangunan Volume 4 Nomor 1 Tahun 2021 
Selain perbedaan pada Tabel 1, juga terdapat perbedaan pada cara perubahan fisik. Pada hunian sementara Lere penghuni melakukan perubahan fisik dengan cara penambahan dan pengurangan elemen. Sedangkan pada hunian sementara petobo, perubahan fisik dilakukan dengan cara penambahan, pengurangan, dan penggabunggan. Berbagai cara perubahan fisik tersebut membentuk tipologi perubahan fisik yang sama antara kedua hunian. Tipologi perubahan fisik yang terbentuk yaitu perubahan fisik dengan menambah ruang, perubahan fisik pada elemen hunian, dan perubahan fisik dengan penambahan ruang dan luas hunian. Berdasarkan tipologi perubahan fisik, pada hunian sementara Lere perubahan paling signifikan terjadi pada elemen hunian, penghuni yang melakukan perubahan pada lantai sejumlah 14 kasus, plafon 9 kasus dan jendela 8 kasus (Lihat Tabel 2).

Tabel 2 menunjukkan perubahan pada elemen hunian di hunian sementara Petobo hanya terjadi pada pintu hunian ( 2 kasus). Berbeda dengan Lere, perubahan pada elemen hunian terjadi pada lantai, plafon, jendela dan pintu.

Wujud perubahan fisik yang diuraikan pada tabel 2 merupakan hasil dari perubahan fisik yang dilakukan oleh penghuni pada hunian sementara. Perubahan fisik yang terjadi menyebabkan hunian sementara berubah dari bentuk asli (Lihat Gambar 2). Garis hitam merupakan ruang eksisting dari hunian sementara, sedangkan garis putus merupakan ruang tambahan atau hasil dari perubahan fisik.

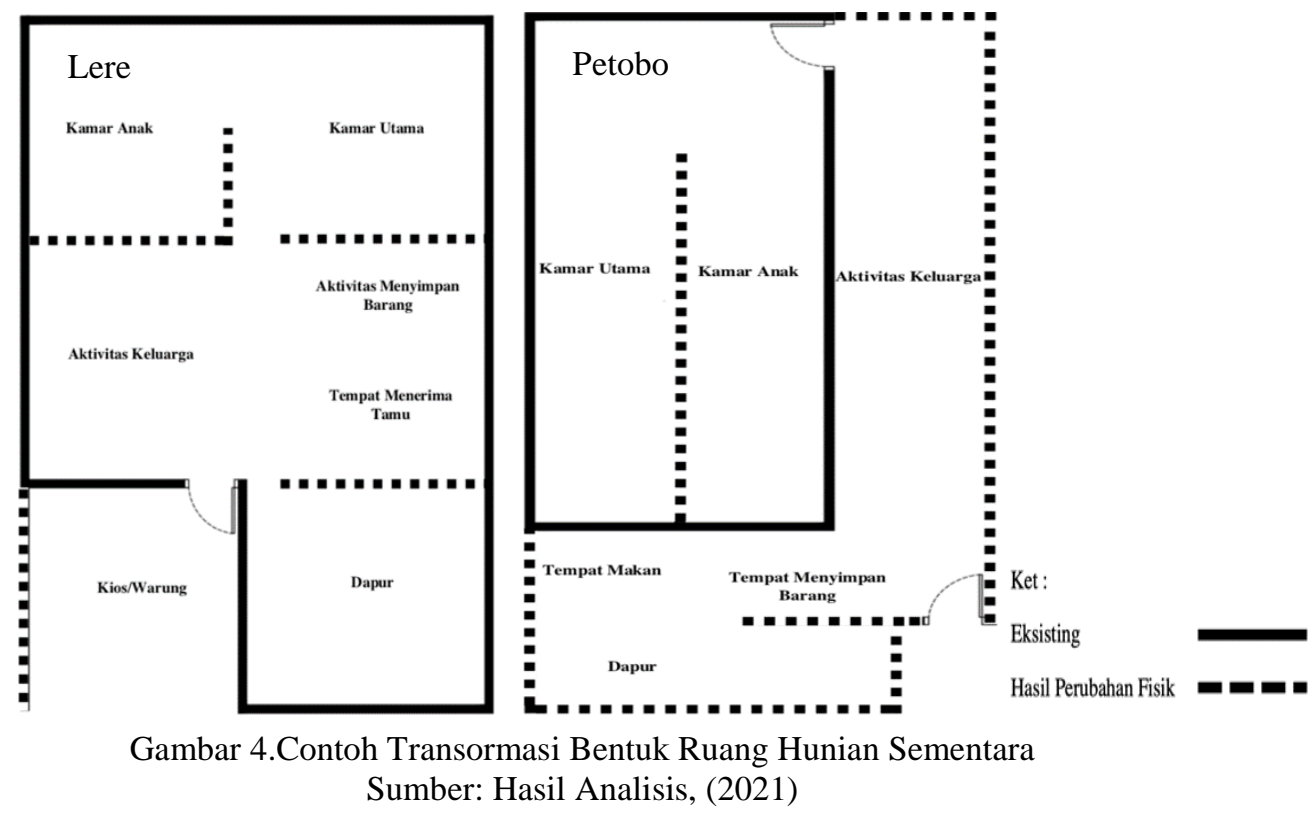

Hal-hal yang mendorong penghuni untuk melakukan perubahan diperoleh dari hasil wawancara pada 30 sampel. Alasan penghuni melakukan perubahan fisik pada hunian sementara Lere dapat dilihat pada Tabel 3.

Alasan aman dan nyaman mendominasi perubahan fisik pada elemen hunian, di hunian sementara Lere. Pada Tabel 3 dapat dilihat penghuni melakukan perubahan pada jendela agar hunian aman sejumlah 12 kasus. Sedangkan perubahan pada lantai agar hunian nyaman sejumlah 15 kasus. Alasan pembatas kamar dan ruang keluarga mendominasi perubahan fisik dengan penambahan ruang, yaitu sejumlah 6 kasus. Alasan hunian lebih luas dan ruang untuk berdagang mendominasi perubahan fisik dengan penambahan ruang dan luas hunian yaitu sejumlah 6 kasus. 
Konsep Kebutuhan Penghuni Dalam Pembangunan Hunian Sementara (Studi Kasus: Hunian Sementara PascaBencana Kota Palu, Indonesia)

\section{Vivi Novianti HY, Ahmad Sarwadi}

Tabel 3. Alasan Perubahan Fisik pada Elemen Hunian

\begin{tabular}{|l|l|}
\hline \multicolumn{1}{|c|}{ Informasi Perubahan Fisik } & \multicolumn{1}{c|}{ Kasus } \\
\hline $\begin{array}{l}\text { Peninggian lantai dilakukan agar saat hujan } \\
\text { air tidak masuk kedalam hunian }\end{array}$ & $01 ; 05 ; 06 ; 08 ; 09 ; 10 ; 13 ; 11 ; 14 ; 15$ \\
\hline $\begin{array}{l}\text { Penambahan kain atau kerdus pada plafon } \\
\text { agar panas dari seng rumah tidak begitu } \\
\text { terasa }\end{array}$ & $09 ; 13 ; 02 ; 06 ; 08 ; 12 ; 01 ; 03$ \\
\hline $\begin{array}{l}\text { Memperbesar jendela untuk mengurangi } \\
\text { rasa panas }\end{array}$ & $02 ; 03 ; 12$ \\
\hline Menambah Jendela untuk mengurangi panas & $04 ; 08 ; 09 ; 02$ \\
\hline $\begin{array}{l}\text { Pintu dibagi menjadi dua bagian, saat siang } \\
\text { hari hanya bagian bawah yang ditutup, agar } \\
\text { angin masuk kedalam hunian }\end{array}$ & $06 ; 08 ; 09 ; 11$ \\
\hline $\begin{array}{l}\text { Penambahan terali kayu,kawat besi dan kain } \\
\text { pada jendela agar hunian aman }\end{array}$ & $01 ; 05 ; 08 ; 13 ; 10 ; 05 ; 06 ; 15 ; 07 ; 11 ; 03 ;$ \\
\hline $\begin{array}{l}\text { Melapisi lantai dengan karpet atau terpal } \\
\text { agar lebih nyaman }\end{array}$ & 14 \\
\hline Menganti pintu hunian untuk keamanan & $04 ; 05,12$ \\
\hline
\end{tabular}

Sumber: Hasil Analisis,2021

Tabel 4. Alasan Perubahan Fisik dengan Penambahan Ruang

\begin{tabular}{|l|l|}
\hline Informasi Perubahan Fisik & Kasus \\
\hline $\begin{array}{l}\text { Sekat dibuat karena penghuni } \\
\text { memiliki anak perempuan }\end{array}$ & $01 ; 04 ; 13$ \\
\hline $\begin{array}{l}\text { Sekat untuk membentuk ruang } \\
\text { kamar }\end{array}$ & $07 ; 02$ \\
\hline $\begin{array}{l}\text { Sekat berfungsi untuk pembatas } \\
\text { kamar dan dapur }\end{array}$ & $06 ; 11 ; 15$ \\
\hline $\begin{array}{l}\text { Sekat berfungsi untuk pembatas } \\
\text { kamar dan ruang keluarga }\end{array}$ & $08 ; 09 ; 10 ; 03 ; 12 ; 14$ \\
\hline $\begin{array}{l}\text { Sekat berfungsi untuk pembatas } \\
\text { kamar dan tempat usaha }\end{array}$ & 05 \\
\hline
\end{tabular}

Sumber: Hasil Analisis, 2021

Tabel 5. Alasan Perubahan Fisik dengan Penambahan Ruang dan Luas

\begin{tabular}{|l|l|}
\hline Informasi Perubahan Fisik & Kasus \\
\hline $\begin{array}{l}\text { Membongkar dinding antara } \\
\text { ruang utama teras agar hunian } \\
\text { lebih luas }\end{array}$ & 09 \\
\hline $\begin{array}{l}\text { Memajukan pintu hingga batas } \\
\text { teras agar hunian luas }\end{array}$ & $07 ; 03 ; 12$ \\
\hline $\begin{array}{l}\text { Penambahan ruang pada bagian } \\
\text { depan untuk berdagang }\end{array}$ & $01 ; 02 ; 15$ \\
\hline $\begin{array}{l}\text { Penambahan tempat istrahat } \\
\text { pada bagian depan }\end{array}$ & $13 ; 14$ \\
\hline
\end{tabular}

Sumber: Hasil Analisis, 2021 
Berikut ini alasan penghuni melakukan perubahan fisik pada hunian sementara Petobo.

Tabel 6. Alasan Perubahan Fisik pada Elemen Hunian

\begin{tabular}{|l|l|}
\hline Informasi Perubahan Fisik & Kasus \\
\hline $\begin{array}{l}\text { Menambah pintu untuk } \\
\text { menggabungkan hunian }\end{array}$ & $11 ; 12$ \\
\hline
\end{tabular}

Sumber: Hasil Analisis, 2021

Perubahan fisik pada elemen hunian hanya terjadi pada 2 kasus, dengan alasan penambahan pintuk untuk menggabungkan 2 hunian. Perubahan fisik ini ditidak siginifikan terjadi di hunian sementara Petobo.

Tabel 7. Alasan Perubahan Fisik dengan Penambahan Ruang

\begin{tabular}{|l|l|}
\hline Informasi Perubahan Fisik & Kasus \\
\hline $\begin{array}{l}\text { Sekat dibuat agar aktivitas } \\
\text { penghuni tidak terllihat dari arah } \\
\text { luar }\end{array}$ & $13 ; 05 ; 04 ; 10 ; 08 ; 01$ \\
\hline $\begin{array}{l}\text { Sekat dibuat untuk membentuk } \\
\text { ruang kamar }\end{array}$ & $03 ; 06 ; 07$ \\
\hline $\begin{array}{l}\text { Sekat sebagai pembatas antar } \\
\text { aktivitas }\end{array}$ & $05 ; 11 ; 02 ; 04 ; 09$ \\
\hline $\begin{array}{l}\text { Sekat dibuat karena penghuni } \\
\text { memiliki anak perempuan }\end{array}$ & $12 ; 14$ \\
\hline
\end{tabular}

Sumber: Hasil Analisis, 2021

Alasan sekat dibuat agar aktivitas pengguni tidak terlihat dari arah luar dan pembatas antar aktivitas mendominasi perubahan fisik dengan penambahan ruang, yaitu sejumlah 6 kasus.

Tabel 8. Alasan Perubahan Fisik dengan Penambahan Ruang dan L
\begin{tabular}{|l|l|}
\hline \multicolumn{1}{|c|}{ Informasi Perubahan Fisik } & Kasus \\
\hline $\begin{array}{l}\text { Penambahan ruang dapur } \\
\text { bagian samping atau depan }\end{array}$ & $13 ; 12 ; 14 ; 09 ; 10$ \\
\hline $\begin{array}{l}\text { Penambahan ruang untuk } \\
\text { berdagang pada bagian samping } \\
\text { atau depan hunian }\end{array}$ & $12 ; 11 ; 14 ; 10$ \\
\hline $\begin{array}{l}\text { Menggabungkan hunian ibu dan } \\
\text { anak agar lebih luas }\end{array}$ & $13 ; 11$ \\
\hline $\begin{array}{l}\text { Menggunakan teras sebagai } \\
\text { ruang keluarga atau ruang tamu }\end{array}$ & $12 ; 11 ; 03 ; 06 ; 09$ \\
\hline $\begin{array}{l}\text { Sumber: Hasil Analisis, 2021 } \\
\text { umber } 109\end{array}$
\end{tabular}

Alasan penambahan dapur dan ruang keluarga mendominasi perubahan fisik dengan penambahan ruang dan luas yaitu sejumlah 5 kasus.

\section{PEMBAHASAN}

Berdasarkan wujud perubahan fisik dan alasan yang mendorong penghuni untuk melakukan perubahan fisik pada hunian sementara, maka dapat diketahui tujuan dari penghuni melakukan perubahan fisik.

Pembahasan pada Tabel 9 mulai menunjukkan bahwa ada kebutuhan penghuni yang kurang pada hunian sementara Lere dan Petobo. Dalam kebijakan BNPB No.7 Tahun 2008 
Konsep Kebutuhan Penghuni Dalam Pembangunan Hunian Sementara (Studi Kasus: Hunian Sementara Pasca-

Bencana Kota Palu, Indonesia)

\section{Vivi Novianti HY, Ahmad Sarwadi}

tentang pemenuhan kebutuhan pada masa tanggap darurat bencana, telah diatur standar minimal kebutuhan pada hunian sementara. Standar minimal kebutuhan yaitu ukuran hunian, aspek keamanan dan kesehatan, serta privasi. Berdasarkan fakta perubahan fisik dan standar minimal kebutuhan hunian sementara, ditemukan penghuni melakukan perubahan fisik karena ada kebutuhan yang kurang dan belum terpenuhi didalam hunian (lihat Tabel 10 dan Tabel 11).

Tabel 9. Tujuan Penghuni Melakukan Perubahan Fisik

\begin{tabular}{|l|l|l|}
\hline $\begin{array}{l}\text { Tipologi } \\
\text { Perubahan Fisik }\end{array}$ & $\begin{array}{l}\text { Tujuan yang Mendorong Penghuni } \\
\text { Melakukan Perubahahan Fisik (Hunian } \\
\text { Sementara Lere) }\end{array}$ & $\begin{array}{l}\text { Tujuan yang Mendorong Penghuni } \\
\text { Melakukan Perubahahan Fisik (Hunian } \\
\text { Sementara Petobo) }\end{array}$ \\
\hline $\begin{array}{l}\text { Perubahan fisik } \\
\text { dengan } \\
\text { menambah } \\
\text { ruang }\end{array}$ & $\begin{array}{l}\text { Perubahan fisik bertujuan untuk } \\
\text { membentuk ruang kamar dan membuat } \\
\text { pembatas antar aktivitas satu dan lainnya. } \\
\text { (lihat Tabel 4). }\end{array}$ & $\begin{array}{l}\text { Perubahan fisik bertujuan untuk } \\
\text { membentuk ruang kamar, penghalang } \\
\text { pandangan dari arah luar, dan pembatas } \\
\text { antar-aktivitas satu dan lainnya (lihat } \\
\text { Tabel 7). }\end{array}$ \\
\hline $\begin{array}{l}\text { Perubahan fisik } \\
\text { pada elemen } \\
\text { hunian }\end{array}$ & $\begin{array}{l}\text { Perubahan fisik bertujuan menciptakan rasa } \\
\text { nyaman dan kebutuhan keamanan } \\
\text { penghuni. (Lihat Tabel 3). }\end{array}$ & $\begin{array}{l}\text { Perubahan fisik bertujuan agar untuk } \\
\text { memperluas hunian (lihat Tabel 6). }\end{array}$ \\
\hline $\begin{array}{l}\text { Perubahan fisik } \\
\text { dengan } \\
\text { penambahan } \\
\text { ruang dan luas } \\
\text { hunian }\end{array}$ & $\begin{array}{l}\text { perubahan fisik bertujuan untuk } \\
\text { memperluas hunian dan membentuk ruang } \\
\text { berdagang (lihat Tabel 5). }\end{array}$ & $\begin{array}{l}\text { Perubahan fisik bertujuan } \\
\text { membentuk ruang dapur, membentuk } \\
\text { ruang berdagang, dan memperluas } \\
\text { hunian. (lihat Tabel 8). }\end{array}$ \\
\hline
\end{tabular}

Sumber: Hasil Analisis, 2021

Tabel 10. Standar Minimal Hunian Sementara dan Fakta Perubahan Fisik di Hunian Sementara Lere

\begin{tabular}{|c|c|c|}
\hline $\begin{array}{l}\text { Standar Minimal } \\
\text { BNPB No. } 7 \\
\text { Tahun } 2008 \\
\end{array}$ & Fakta Perubahan Fisik & Kondisi Hunian Sementara Lere \\
\hline $\begin{array}{l}\text { Berukuran } 3 \\
\text { (tiga) meter } \\
\text { persegi per } \\
\text { orang. }\end{array}$ & $\begin{array}{l}\text { Fakta perubahan fisik penghuni } \\
\text { melakukan penambahan luas hunian } \\
\text { dengan menambah ruang pada bagian } \\
\text { depan hunian, memanjukan dinding dan } \\
\text { memajukan pintu kebagian depan. }\end{array}$ & $\begin{array}{l}\text { Luas hunian sementara } 3 \times 4 \text { Lere telah } \\
\text { sesuai dengan standar BNPB. Namun } \\
\text { pada hunian sementara Lere } \\
\text { menunjukkan indikasi kurang terpenuhi } \\
\text { keinginan penghuni akan luas hunian } \\
\text { sementara }\end{array}$ \\
\hline \multirow[t]{2}{*}{$\begin{array}{l}\text { Memiliki } \\
\text { persyaratan } \\
\text { keamanan dan } \\
\text { kesehatan. }\end{array}$} & $\begin{array}{l}\text { Fakta perubahan fisik penghuni } \\
\text { meninggikan lantai agar air tidak masuk } \\
\text { kedalam hunian, menambahakan kain } \\
\text { atau kerdus pada plafon untuk } \\
\text { mengurangi panas, dan memperbesar } \\
\text { jendela untuk mengurangi panas. }\end{array}$ & $\begin{array}{l}\text { Pada hunian sementara Lere } \\
\text { menunjukkan indikasi kurang terpenuhi } \\
\text { rasa nyaman menempati hunian atau } \\
\text { hunian sementara Lere kurang } \\
\text { memenuhi standar kesehatan bangunan }\end{array}$ \\
\hline & $\begin{array}{l}\text { Fakta perubahan fisik penghuni } \\
\text { menambahkan terali kayu, kawat besi, } \\
\text { jaring-jaring besi dan menganti pintu agar } \\
\text { penghuni merasa aman }\end{array}$ & $\begin{array}{l}\text { Pada hunian sementara Lere } \\
\text { menunjukkan indikasi kurang terpenuhi } \\
\text { rasa aman penghuni di dalam hunian }\end{array}$ \\
\hline $\begin{array}{l}\text { Menjamin privasi } \\
\text { antar jenis } \\
\text { kelamin dan } \\
\text { berbagai } \\
\text { kelompok usia }\end{array}$ & $\begin{array}{l}\text { Fakta perubahan fisik penghuni } \\
\text { melakukan penambahan ruang dengan } \\
\text { menyekat karena alasan memiliki anak } \\
\text { perempuan dan untuk membuat ruang } \\
\text { kamar. }\end{array}$ & $\begin{array}{l}\text { Pada hunian sementara Lere } \\
\text { menunjukkan indikasi belum tepenuhi } \\
\text { privasi penghuni di dalam hunian } \\
\text { sementara }\end{array}$ \\
\hline
\end{tabular}

Sumber: Hasil Analisis, 2021 
Dalam Tabel 10 dapat dilihat bahwa ukuran hunian sementara lere telah sesuai dengan standar BNPB. Namun demikian, kebutuhan rasa nyaman dan aman penghuni kurang terpenuhi, serta kebutuhan privasi penghuni belum terpenuhi. Sedangkan pada hunian sementara Lere telah terpenuhi kebutuhan rasa nyaman dan aman penghuni namun belum terpenuhi kebutuhan privasi penghuni. Berdasarkan fakta perubahan fisik, selama 2 tahun penghuni tidak melakukan perubahan fisik yang signifikan pada elemen-elemen hunian (lihat Tabel 6). Kondisi ini menunjukkan hunian sementara Lere telah sesuai dengan standar BNPB.

Tabel 11. Standar Minimal Hunian Sementara dan Fakta Perubahan Fisik di Hunian Sementara Petobo

\begin{tabular}{|l|l|l|}
\hline $\begin{array}{l}\text { Standar Minimal } \\
\text { BNPN No. 7 Tahun }\end{array}$ & \multicolumn{1}{|c|}{ Fakta Perubahan Fisik } & \multicolumn{1}{|c|}{ Kondisi Hunian Sementara Petobo } \\
\hline $\begin{array}{l}\text { Berukuran 3 (tiga) } \\
\text { meter persegi per } \\
\text { orang. }\end{array}$ & $\begin{array}{l}\text { Fakta perubahan fisik, penghuni } \\
\text { melakukan penambahan luas hunian } \\
\text { dengan membuat ruang untuk } \\
\text { berdagang dan ruang dapur }\end{array}$ & $\begin{array}{l}\text { Luas Hunian sementara Petobo 3x4 telah } \\
\text { sesuai dengan standar BNPB. Namun pada } \\
\text { hunian sementara petobo menujukkan } \\
\text { indikasi kurang terpenuhi keinginan } \\
\text { penghuni akan luas hunian }\end{array}$ \\
\hline $\begin{array}{l}\text { Memiliki } \\
\text { persyaratan } \\
\text { keamanan } \\
\text { kesehatan. }\end{array}$ & $\begin{array}{l}\text { fakta perubahan fisik, penghuni tidak } \\
\text { melakukan perubahan fisik pada } \\
\text { plafon, lantai, jendela dan pintu }\end{array}$ & $\begin{array}{l}\text { Pada hunian sementara Petobo } \\
\text { menunjukkan indikasi telah terpenuhi rasa } \\
\text { nyaman dan aman penghuni didalam } \\
\text { hunian }\end{array}$ \\
\hline $\begin{array}{l}\text { Menjamin privasi } \\
\text { antar } \\
\text { kelamin jenis } \\
\text { berbagai } \\
\text { kelompok usia }\end{array}$ & $\begin{array}{l}\text { Fakta perubahan fisik penghuni } \\
\text { melakukan penambahan ruang dekat } \\
\text { menyekat karena alasan aktivitas } \\
\text { penghuni tidak terllihat dari arah luar, } \\
\text { membentuk ruang kamar, dan } \\
\text { penghuni memiliki anak perempuan }\end{array}$ & $\begin{array}{l}\text { Pada hunian sementara Petobo } \\
\text { menunjukkan indikasi belum terpenuhi } \\
\text { privasi penghuni didalam hunian }\end{array}$ \\
\hline
\end{tabular}

Sumber: Hasil Analisis, 2021

Penghuni hunian sementara Lere dan Petobo mulai melakukan perubahan fisik rata-rata setelah 3 bulan menempati hunian sementara. Pada hunian sementara Lere, penghuni pertama kali melakukan perubahan fisik pada elemen hunian untuk memenuhi kebutuhan akan rasa nyaman dan aman. Sedangkan pada hunian sementara Petobo penghuni pertama kali melakukan perubahan fisik dengan penambahan ruang untuk memenuhi kebutuhan privasi.

Sudut padang yang digunakan dalam menyusun konsep hunian sementara yaitu menggunakan sudut pandang Maslow. Teori Maslow dalam Lutfiah (2010) menjelaskan hirarki kebutuhan individu atau kelompok pada sebuah rumah. Dalam teori Maslow hirarki pertama kebutuhan fisiologis, kebutuhan rasa aman, kebutuhan pemenuhan hubungan sosial, kebutuhan penghargaan diri dan kebutuhan aktualisasi diri. . Hunian sementara berbeda dengan hunian pada umumnya, penggunaanya yang sementara menyebabkan kebutuhan yang perlu disediakan merupakan kebutuhan paling dasar.

Berdasarkan fenomena perubahan fisik terdapat 3 kebutuhan pada hunian sementara berdasarkan aspirasi penghuni. Pertama perubahan fisik pada elemen hunian dilakukan penghuni untuk mencapai kebtuhan fisik. Kedua perubahan fisik dengan penambahan ruang dilakukan penghuni untuk mencapai kebutuhan privasi. Ketiga perubahan fisik dengan penambahan ruang dan luas dilakukan untuk mencapai kebutuhan fungsional. Pada hunian sementara Lere penghuni pertama kali mencapai kebutuhan fisik, sedangkan hunian sementara petobo mencapai kebutuhan privasi. Berdasarkan fakta perubahan fisik hunian sementara 
Konsep Kebutuhan Penghuni Dalam Pembangunan Hunian Sementara (Studi Kasus: Hunian Sementara PascaBencana Kota Palu, Indonesia)

Vivi Novianti HY, Ahmad Sarwadi

Petobo telah memenuhi kebtuhan fisik bagi peghuninya (aman dan nyaman). Kondisi tersebut menunjukkan kebutuhan paling dasar pada hunian sementara yaitu kebutuhan fisik.

Kebutuhan fisik merupakan kebutuhan dasar pada hunian sementara. Fisik hunian sementara harus memenuhi kebutuhan kenyamanan dan keamanan penghuni.

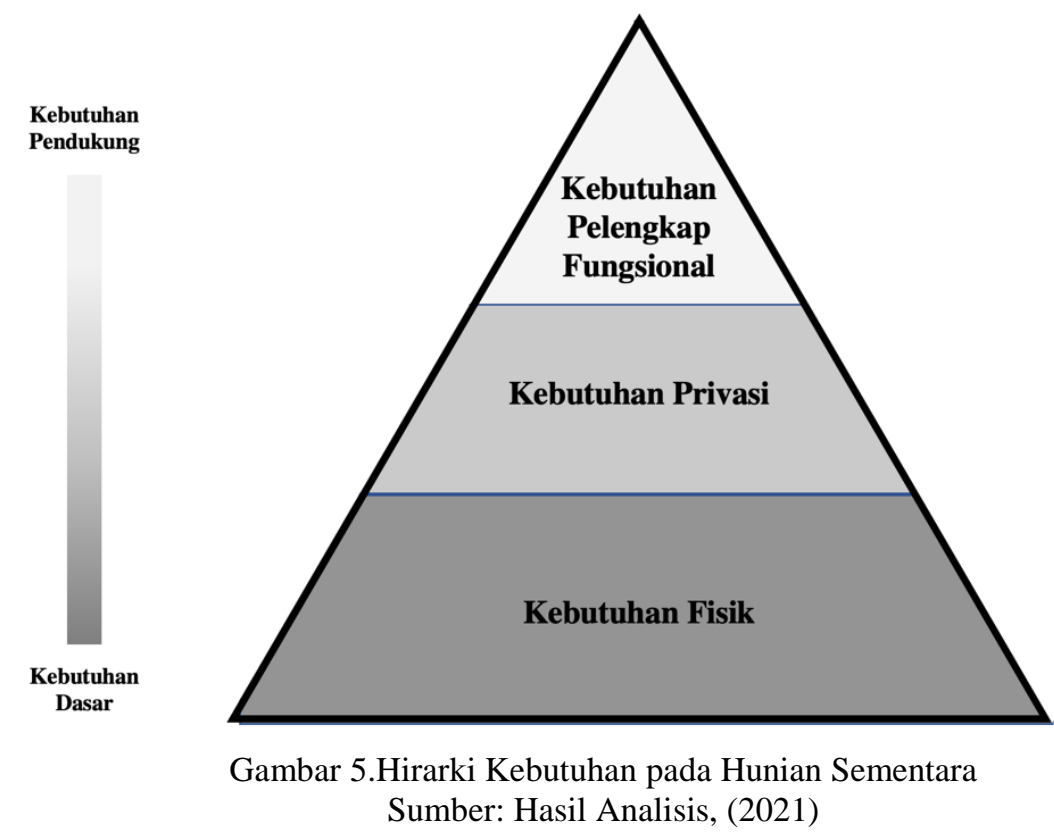

Kebutuhan fisik dapat dicapai apabila hunian sementara dibangun seperti hunian sementara Petobo.Hunian sementara Petobo merupakan jenis hunian deret dengan bentuk bangunan semi panggung. Berdasarkan fakta perubahan fisik, hunian ini dianggap telah memenuhi kebutuhan kenyamanan dan keamanan penghuni
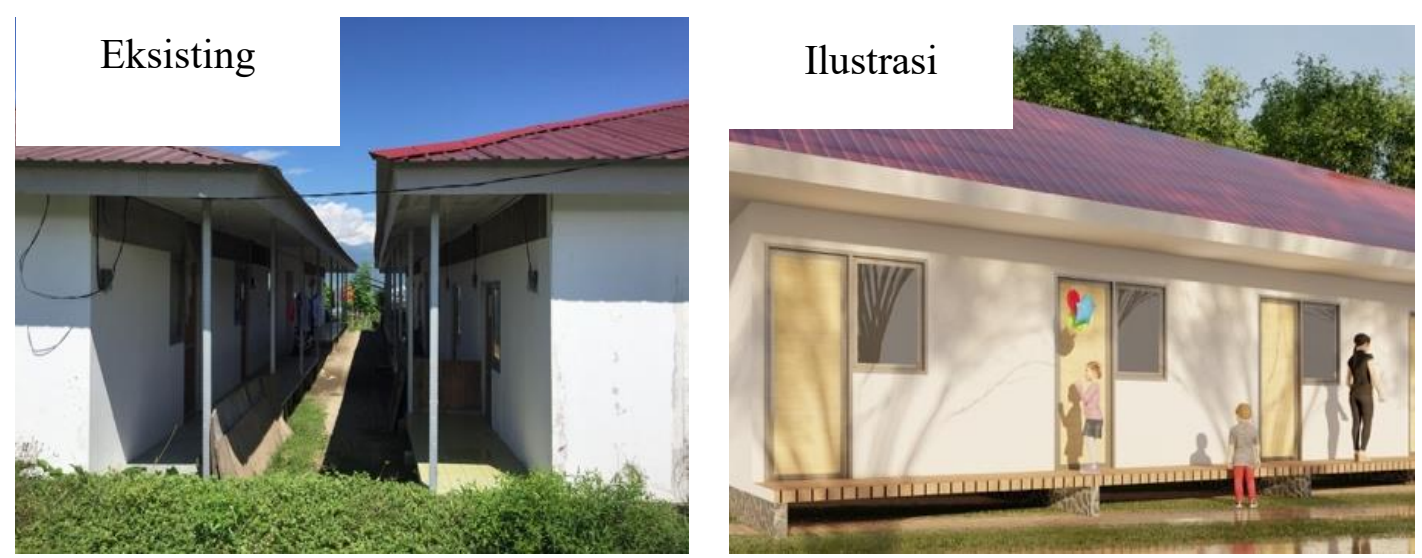

Gambar 6.Ilustrasi Hunian Sementara untuk Mendukung Kebutuhan Keamanan dan Kenyamanan Sumber: Hasil Analisis, (2021)

Kebutuhan privasi merupakan kebutuhan yang disediakan setelah kebutuhan dasar terpenuhi. Hunian semenatara harus memiliki ruang privat yang dapat digunakan sebagai batasan aktivitas antara anak dan orang tua atau penghuni dengan orang lain.

Kebutuhan privasi di hunian sementara dapat dicapai dengan menggunakan batasan fisik yang sifatnya permanen atau non permanen (T.Hall dalam Lang (1987)). Di hunian sementara Lere terdapat sekitar $73 \%$ hunian menggunakan tripleks (permanen) sebagai sekat dan $26 \%$ 
menggunakan kain (tidak permanen). Di hunian sementara Petobo, sekitar $68 \%$ hunian menggukan sekat triplek (permanen), 26\% menggunakan kain (tidak permanen) dan 6\% menggunakan lemari (tidak permanen).

Kebutuhan fungsional merupakan kebutuhan pelengkap pada hunian sementara. Penglengkap dapat dibagai menjadi umum dan privat. Pelengkap yang penggunaanya umum adalah kamar mandi umum. Pelengkap yang penggunaannya privat yaitu dapur.

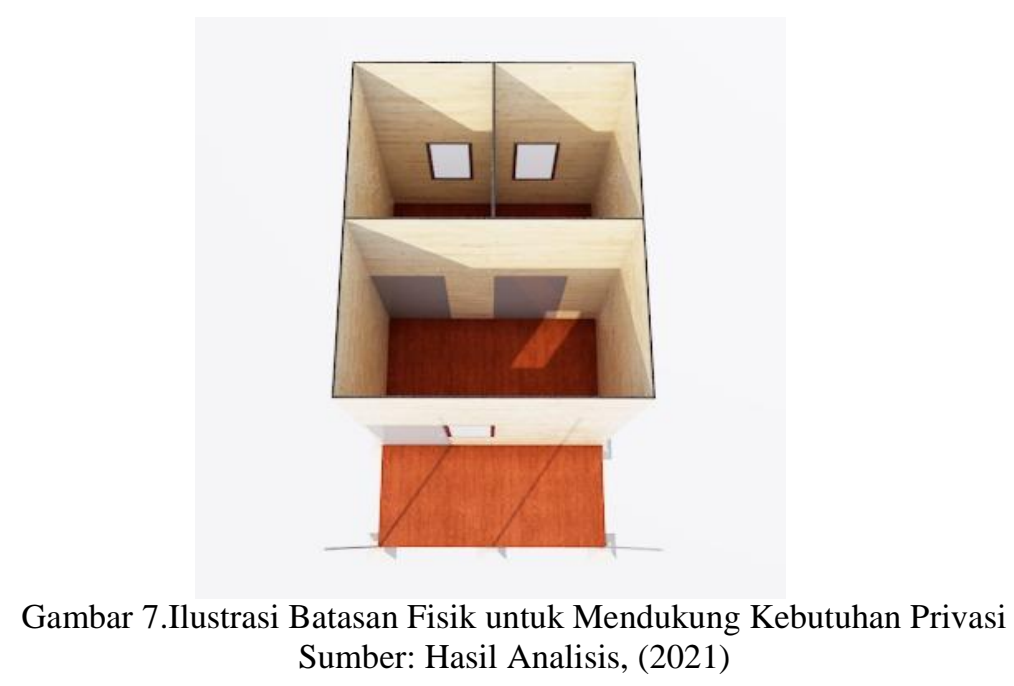

Pada kawasan hunian sementara Lere, dilengkapi dengan fasilitas musholla dan kamar mandi umum untuk fasilitas bersama. Sedangkan tempat dapur disediakan pada setiap hunian. Berdasarkan fakta perubahan fisik, jenis fasilitas pada hunian sementara Lere diindikasikan telah sesuai dengan kebutuhan penghuni. Berbeda dengan hunian sementara Petobo, semua fasilitas selain hunian digunakan secara bersama. Kondisi ini menyebabkan penghuni melakukan perubahan fisik dengan membuat dapur dibagian luar atau dalam hunian. Kondisi ini mengindikasikan dapur yang penggunaanya secara umum pada kawasan hunian sementara kurang sesuai dengan kebutuhan penghuni. Pada kedua kawasan hunian sementara tidak ditemukan penghuni yang menambahkan kamar mandi pada bagian dalam hunian atau sekitar hunian. Hal ini mengindikasikan kawasan hunian sementara dengan fasilitas kamar mandi umum telah sesuai dengan kebutuhan penghuni.

\section{KESIMPULAN}

Penghuni melakukan adaptasi pada bentuk fisik hunian sementara karena terdapat kebutuhan yang kurang dan belum terpenuhi. Berdasarkan kasus perubahan fisik pada hunian sementara pasca-bencana Kota Palu, maka konsep hunian sementara yang dapat memenuhi kebutuhan penghuni sebagai berikut :

a. Kebutuhan fisik menjadi dasar kebutuhan pada hunian sementara. Fisik hunian sementara harus memenuhi kebutuhan kenyaman dan keamanan penghuni. Hunian sementara dengan tipe pola hunian deret dinilai penghuni telah memenuhi kebutuhan fisik.

b. Kebutuhan privasi merupakan kebutuhan kedua yang dibutuhkan penghuni pada hunian sementara. Hunian semenatara harus memiliki ruang privat yang dapat digunakan sebagai batasan aktivitas antara anak dan orang tua atau penghuni dengan orang lain.

c. Kebutuhan fungsional adalah kebutuhan pelengkap pada hunian sementara. Penglengkap dibagi penggunaannya secara umum umum dan privat. Pelengkap yang 
Konsep Kebutuhan Penghuni Dalam Pembangunan Hunian Sementara (Studi Kasus: Hunian Sementara PascaBencana Kota Palu, Indonesia)

Vivi Novianti HY, Ahmad Sarwadi

penggunaanya umum adalah kamar mandi umum. Pelengkap yang penggunaannya privat yaitu dapur.

\section{REKOMENDASI}

a. Desain bangunan hunian sementara Petobo dapat digunakan sebagai standar minimal bnagunan hunian sementara pada masa tanggap darurat.

b. Pemerintah perlu menyusun pedoman teknis pembangunan dan pemenuhan kebutuhan hunian sementara pada masa tanggap darurat

\section{DAFTAR PUSTAKA}

Badan Nasional Penanggulangan Bencana. (2008). Peraturan Kepala Badan Nasional Penanggulangan Bencana No. 7 Tahun 2008 tentang Pedoman Tata Cara Pemberian Bantuan Pemenuhan Kebutuhan Dasar. Sekretariat Negara. Jakarta.http://ditjenpp.kemenkumham.go.id/arsip/bn/2014/bn1407-2014.

Ernawati dan Giyarsih. (2011). Penyesuaian Diri Penguhuni Rumah Susun Terdahap Lingkungan Tempat Tinggal. Yogyakarta: Balai Pelestarian Sejaaarah dan Nilai Tradisional Yogyakarta.

Kurniati dan Kusuma. (2014). Adaptasi Perilaku dan Modifikasi sebagai Proses Menciptakan Hunian Ideal Bagi Penghuni Perumahan Massal. Prosiding Temu Ilmiah IPLBI.

Lutfiah. (2010). Perubahan Bentuk dan Fungsi Hunian pada Rumah Susun Pasca Penghunian. Jurnal Ruang.

Lang, Jon. 1987. Creating Architectural Theory: The Role of the Behavioral Sciences in Environmental Design. New York: Van Nostrand Reinhold.

M. Sesotyaningtyas, Pratiwi, dan Setyono. (2015). Transformasi Hunian Dengan Perspektif Spasial dan Tatanan Budaya: Komparasi Permukiman Kumuh Bang Bua, Thailand dan Kampung Naga Indonesia. Journal of Geomatics and Planning

Omar, Endut dan Saruwono. (2017). Adapting by Altering: Spatial Modifications of Terraced Houses in The Klang Valley area. Journal of Environmen-Behavior Studies.

Pramono. (2018). Strategi Adaptasi dalam Huntap Karang Kendal, Dusun Balong, Desa Umbulharjo, Kecamatan Cangkringan, Kabupaten Sleman Daerah Istimewa Yogyakarta. Universitas Gadjah Mada

Pemerintah Provinsi Sulawesi Tengah. (2019). Peraturan Gubernur Sulawesi Tengah No. 10 Tahun 2019 tentang Rencana Rehabilitasi dan Rekontruksi Pascabencana. Sekretariat Daerah. Sulawesi Tengah. "Https://Jdih.Sultengprov.Go.Id/Peraturan/Pergub\%20nomor\%2010\%20tahun\%202019

Rahim dan Hashim. (2018). Behavioral Adaptation of Malay Families and Housing Modification of Terrace Houses in Malaysia. Asian Journal of Environment-Behavior Studies. 